\title{
The Efficacy of Teaching English for Engineering Students
}

M.G.Meedphin Arasi, Assistant Professor (Grade-II), Department of English, R.M.K. Engineering College, Kavaraipettai 601206, Chennai, India.

mgm.sh@rmkec.ac.in

\begin{abstract}
India is a nation that has an adequate number of engineering colleges but, the language proficiency of students is not to the mark, and owing to this, many of them are to earn only a meagre salary. As communicative skill is the yardstick for their placements, it is necessary to improve their language skills (LSRW). This paper briefly explains the various causes of engineering students' poor language skills along with measures to have a successful career.
\end{abstract}

\section{Introduction}

Engineering is an elite profession that needs teamwork for ensuring maximum productivity and workflow. Engineering courses not only augment students' critical and analytical thinking but also enable their life skills to independently analyze their problems with solutions. Engineering students after completing their engineering may shine in various fields as Agricultural engineers, Biomedical engineers, Aerospace Engineers, Civil Engineers, and so on. But for any field, their effective communication is a must and therefore it is mandatory to horn up their spoken and written language. Though many of the engineering students are from matriculation or CBSE backgrounds, most of them stumper in their oral and written English. A few students are from a rural background and they would have completed their school education by rote memory rather than applying their creativity. This category of students can effortlessly recite a poem or a formula but they can't create anything of their own. This happens because of their ineffective writing skills and lack of imaginative ideas. As language plays a vital role in one's communication, students must practice all the four language skills (Listening, Speaking, Reading, and Writing) from their childhood. They must thoroughly learn the grammar rules and apply the same while framing sentences for varied situations. In short, basic language skills ought to be adopted from their school days by actively participating in all their language hours.

\section{English in Engineering Curriculum}


Students generally opt for engineering as a course of study to complete their degree within a short span along with a high salary package. This would be their dream in the very beginning. But once they start studying, they feel very difficult to cop up their subjects due to their inadequate language skills. Though bridge courses are conducted in the very beginning to horn up their language skills, their understanding of the concepts is still a challenge. As they are very reluctant in improving their oral and written English, they score only fewer marks in all the subjects and this in turn highly affects their overall GPA. If they realize the importance of English and take efforts for developing the same, they will undoubtedly bring their standard which helps them excel in their personal and professional prospects. At least by knowing this, they must well practice their English with utmost passion and involvement. This helps them get placed in reputed concerns with a high salary package. English laboratory is a part of the Engineering curriculum to horn up students' presentation and interview skills in addition to their Semester I \& II English. Assignments, mini-projects, and seminars are to help them showcase their talents. But students submit them without applying their creativity or originality. They simply download and submit the same piece of information without applying their paraphrasing strategy.

\section{Common Grammatical Mistakes Committed by Engineering Students}

Grammar is a bugbear to most engineering students and they are quite oblivious to grammar rules and their applications. Lack of grammatical accuracy affects their writing and presentation skills. For example, the phrases or expressions like "forward to" and "with a view to" must grammatically agree gerund or "ing" form of a verb and not a 'bare infinitive'. But students use only a "bare infinitive" verb with these two expressions. Conversion of statements using different discourse markers such as "on account of", "owing to", "so that' etc is also a big challenge to them. As these transition words show coherence between sentences, it is mandatory to learn them properly. They must also learn the application of all the other linkers to indicate comparison, contrast, purpose, cause, effect, condition, time, clarification, etc. to efficiently handle various situations. Tenses play a vital role almost in all situations and therefore students must be thorough with the application of all the tenses and their structures. After learning tenses, they must know about passive verbs and their uses. Most of the engineering students don't have a thorough idea about the passive markers "be", 'being" and "been and they use them inappropriately in passive statements. While "be "is used with simple verb forms (simple present/simple past/simple future), "being" is used with continuous forms (present continuous/past continuous/future continuous), and "been "is used 
with perfect tense forms (present perfect/past perfect/future perfect). There is no passivity for all the perfect continuous tenses (present perfect continuous/past perfect continuous/future perfect continuous).

Conditional statements are the most nebulous statements owing to the application of conditional verbs and conditional words. Students stumble in identifying the various types of conditionals- probable, improbable, impossible, and imaginary. They very often use past perfect in improbable conditional (Type II) and past modal in impossible conditionals (Type III). For indicating probability, one must use only a simple present in the conditional clause and a simple present/simple future/present modal in the main clause based on the type of actions. While indicating any general scientific actions, one must use only a simple present and for the other actions, a simple future should be used. "If you meet your sales target, you will win that European tour." In case the given action indicates possibility, present modals (can/may) may be used. While improbable conditionals grammatically agree past modal (Would+main verb/would+be+pptv) like "If you met your sales target, you would win that European tour.", impossible conditional agrees only past perfect modal (would+have+pptv/would+have+been+pptv). "If you had met your sales target, you would have won that European tour." The `voice` of the verbs may be either active or passive and it should be determined of its sense.

Identifying the difference between a gerund and the present participle is a great problem to engineering students as both are the same in structures ie, 'Verb+ing'. If students know about their functions, they may confidently use them in their sentences. Gerund always functions as a noun whereas the present participle always functions only as a verb. The other remarkable mistakes committed by engineering students are the usage of modal verbs for expressing different moods of actions such as permission, compulsion, request, necessity, suggestion, etc. Mostly they handle the modals inappropriately in various situations. Can, could, will, would are the regular modals for indicating request, and can and may are used for expressing possibility. While must, should, has to, have to, and ought to are used to indicate compulsion, shall and could are used to indicate suggestion. Though grammar is a scare to many of the students, they must take efforts to learn the entire grammar rules thoroughly so that they may handle any formal or informal situations quite competently.

\section{Impact of Language Skills}


Poor reading skill is another cause for ineffective communication. Reading helps one practice or exercise comprehension along with analytical abilities. It fires up students' imagination and stimulates their memory to recall information. It emboldens mental muscles and augments brain functioning, vocabulary, knowledge, memory, and theory of mind. It fosters one's concentration and improves writing skills. It reduces stress, augments mental health, and helps us stay long. It also lets us learn new things to succeed in our work and relationship. It makes us smarter and lights up our creativity and imagination. It makes our brain more active with free thoughts and imagination. As a mark of the quotation "Today a reader, tomorrow a leader" by Margaret Fuller, all the three levels of reading-habitual, intensive, and extensive help students acquire knowledge and build up vocabulary.

Speaking is a problem for most engineering students. As they have no oral practice, they feel very difficult to manage the oral rounds in their job interviews. If they develop their spoken English, their presentation skills will automatically be boosted. While speaking English, they may initially commit a great number of mistakes and later on, they may slowly rectify such mistakes, and one day they will surely excel in their speaking. Students must volunteer themselves to actively participate in seminars, conferences, and workshops to bump up their presentation skills. Due to their speaking practice, they can notch up great heights in their career too. Above all, if they are good at their speaking, they can congruously convey their message.

Writing is a challenge to most engineering students. While drafting official letters, they abundantly commit grammatical fluffs with inappropriate linkers. Whenever a group of students is assigned to write letters for similar purposes, they simply copy-paste the content from their fellow students and forward the same without minding their originality and creativity. Their lethargic and serious attitudes hamper their writing skill and as a result of this, they suffer in their academic writings. If they are serious in writing, there will be a progression in it. To master writing, the students must actively participate in various writing competitions such as elocution, picture description, essay writing, creative writing, poem writing, and so on.

\section{Conclusion}

To conclude, learning a second language may be a complicacy to many engineering students. But there is no substitute for their hard work. If engineering students beef up their language 
skills, they may be very effective in classroom conversations, lectures, assignments, and projects. As the mark of the quotation by William Butler Yeats "Think like a wise man but communicate in the language of the people," students must learn and communicate English effectively by brushing up all their language skills.

\section{References}

1. https://preply.com/en/blog/the-importance-of-english-in-today-s-world/

2. https://www.grammarly.com/blog/conditional-sentences/

3. https://www.cgcc.edu/literacy/resources/four-basic-language-skills 